\title{
Echolocation behavior of harbor porpoises Phocoena phocoena around chemically enhanced gill nets
}

\author{
Tara M. $\operatorname{Cox}^{1,2, *}$, Andrew J. Read ${ }^{1}$ \\ ${ }^{1}$ Nicholas School of the Environment \& Earth Sciences, Duke University Marine Laboratory, 135 Duke Marine Lab Road, \\ Beaufort, North Carolina 28516, USA \\ ${ }^{2}$ Present address: US Marine Mammal Commission, 4340 East-West Highway, Room 905, Bethesda, Maryland 20814, USA
}

\begin{abstract}
The echolocation behavior of harbor porpoises Phocoena phocoena around gillnets was monitored to test their response to chemically $\left(\mathrm{BaSO}_{4}\right)$ enhanced gill nets, designed to be more acoustically reflective than commercial nets. Field trials were conducted between 22 July and 31 August 2000 in the Bay of Fundy, Canada. Echolocation clicks were continuously monitored with Porpoise Echolocation Detectors (PODs). Commercial and experimental (chemically enhanced) gill nets were set for groundfish in water depths from 100 to $130 \mathrm{~m}$. Echolocation occurrence (the proportion of $10 \mathrm{~s}$ intervals during which clicks were detected) and echolocation rate (the number of clicks $\mathrm{h}^{-1}$ ) were measured. The PODs varied in their detection ability, so comparisons between commercial and enhanced nets were made with individual PODs. Neither echolocation rate nor occurrence differed with net type for any POD. Significantly more echolocation was detected during the day than at night. Echolocation rate and echolocation occurrence varied with depth and location, possibly reflecting concomitant variation in the relative abundance of porpoises and/or their prey. We conclude that porpoises do not respond to the acoustic reflectivity of the modified nets. Rather, the effectiveness of these nets is apparently due to other factors, such as their physical properties, particularly their stiffness.
\end{abstract}

KEY WORDS: Echolocation · Harbor porpoises $\cdot$ By-catch $\cdot$ Fisheries

\section{INTRODUCTION}

Odontocetes possess a sophisticated echolocation system, which they use in foraging and navigation (Tyack 1999). However, most research on odontocete echolocation has been conducted in captivity (Au 1993), and we know very little about the ecological and behavioral contexts in which dolphins and porpoises echolocate in the wild. Many questions remain, e.g. in what situations, and how often, dolphins and porpoises echolocate, how they use sound to select and capture prey, and how they navigate around obstacles (Tyack 1999). A few researchers have begun to examine these questions (e.g. Jones \& Sayigh 2002), but our understanding of the echolocation behavior of free-ranging odontocetes remains very limited.
Understanding the context(s) in which echolocation is used has direct relevance to our understanding of the by-catch of dolphins and porpoises in fisheries. Hundreds of thousands of small cetaceans die each year in fishing gear worldwide, mostly in gill nets (Read et al. 2003), and as a result, several species are being threatened with extinction (Reeves et al. 2003). How porpoises and dolphins become entangled is poorly understood (Perrin et al. 1994). Such by-catches are particularly puzzling given the ability of small cetaceans to use echolocation (and vision) to detect and avoid objects in controlled trials. For example, in captive environments, dolphins and porpoises can detect gill nets at sufficient distances to avoid entanglement (Hatakeyama \& Soeda 1990, Au 1994, Kastelein et al. 2000). Nevertheless, entanglement 
occurs frequently and is a serious conservation problem for many species.

It is likely that porpoises and dolphins do not echolocate constantly (Cox et al. 2001, Jones \& Sayigh 2002). Therefore, entanglement may stem from 1 or more of 3 scenarios: (1) odontocetes do not detect the net while echolocating, or do not recognize it as a barrier; (2) odontocetes detect the net, but make a fatal navigational error; or (3) odontocetes become entangled in the net while not echolocating.

Scientists, fisheries managers and particularly fishermen have developed and tested a variety of potential mitigation strategies to address the by-catch of small cetaceans, including the acoustic modification of gill nets. Early attempts to increase the acoustic reflectivity of gill nets met with very limited success (see Perrin et al. 1994 for review). Such modifications included the incorporation of air-filled monofilament, multifilament line and weighted vertical lines in gill nets to make them more detectable (e.g. Dawson 1994, Silber et al. 1994). Hatakeyama et al. (1994) tested a variety of these modifications to reduce by-catch of Dall's porpoises Phocoenoides dalli in a commercial salmon drift net fishery, but their results were inconclusive. Hatakeyama et al. (1994) concluded that passive acoustic modifications were not a feasible alternative to reduce the by-catch of dolphins and porpoises in gill nets. Based on these results and other inconclusive studies (Silber et al. 1994), researchers turned their attention to other mitigation strategies, such as the use of acoustic alarms or 'pingers' (e.g. Kraus et al. 1997). To date, no gillnet fishery has adopted the use of passive acoustic modifications, and few additional research projects have addressed this subject. In 2000, the International Whaling Commission's (IWC) scientific committee reviewed studies involving acoustic modifications to gill nets, and determined that such modifications had little effect on reducing by-catch (IWC 2001).

However, one of the studies (Trippel et al. 2003) reviewed by the IWC was the catalyst for further research in this area. Trippel et al. (2003) developed a monofilament net filled with barium sulfate $\left(\mathrm{BaSO}_{4}\right)$, to increase the acoustic reflectivity of the net ( $\mathrm{N}$. Holy pers. comm.) and demonstrated a significant reduction in by-catch of harbor porpoises using these nets in the Bay of Fundy, Canada. Larsen et al. (2002) also reported that nets modified with another chemical (iron oxide) reduced by-catches of harbor porpoises in trials conducted in the North Sea. However, the 2 studies differed markedly in their results: Trippel et al. (2003) reported a significant increase in the acoustic reflectivity in the chemically enhanced net, whereas Larsen et al. (2002) found no significant difference in reflectivity between modified and commercial nets.
Therefore, the mechanism by which these chemically modified nets reduce by-catch remains unclear.

For acoustically modified nets to be effective, porpoises must echolocate in the vicinity of the nets and respond appropriately to echoes received. To date, there have been no observations of the behavior of dolphins or porpoises around chemically modified gill nets, but we hypothesize that animals might approach the modified nets to investigate their structure or, alternatively, move away from the nets after recognizing them as a potentially dangerous barrier. In either scenario, we would expect echolocation behavior to differ in the presence of chemically enhanced and commercial (control) nets. We base these predictions on observations of the behavior of porpoises and dolphins around nets in other contexts. For example, Kastelein et al. (1995) showed that 2 captive harbor porpoises echolocated more frequently when simulated fishing nets were introduced to their tanks.

In the present study, we investigated the echolocation behavior of harbor porpoises Phocoena phocoena around gill nets in the Bay of Fundy, Canada, to test whether they echolocated more or less frequently around chemically modified gill nets. To do so, we placed echolocation detectors on both standard commercial and chemically enhanced gill nets, and evaluated the null hypothesis that there would be no significant difference in echolocation behavior between the 2 net types. If porpoises responded to the acoustic reflectivity of the net in some way, we would expect some change in the echolocation behavior of porpoises around the different types of nets.

\section{MATERIALS AND METHODS}

In cooperation with a concurrent study by the Canadian Department of Fisheries and Oceans, we placed an observer (T. M. Cox) on a commercial gillnet vessel fishing in the Bay of Fundy near Grand Manan Island, New Brunswick, Canada (Fig. 1). Hauls of standard commercial nets (control) and nets filled with $\mathrm{BaSO}_{4}$ (experimental; see Trippel et al. 2003) were observed. The vessel fished $15 \mathrm{~cm}$ stretched mesh, monofilament (strand diameter: 0.57 to $0.70 \mathrm{~mm}$ ) gill nets, set on the bottom to catch cod Gadus morhua, pollock Pollachius virens, haddock Melanogrammus aeglefinus, and white hake Urophycis tenuis. Type of net (control or experimental), position (latitude, longitude), depth set, soak time, species and number of fish caught, and number of porpoises caught for each haul were recorded. The time between setting and hauling each net (soak time) varied considerably, so we corrected all values of fish catch for this parameter. 


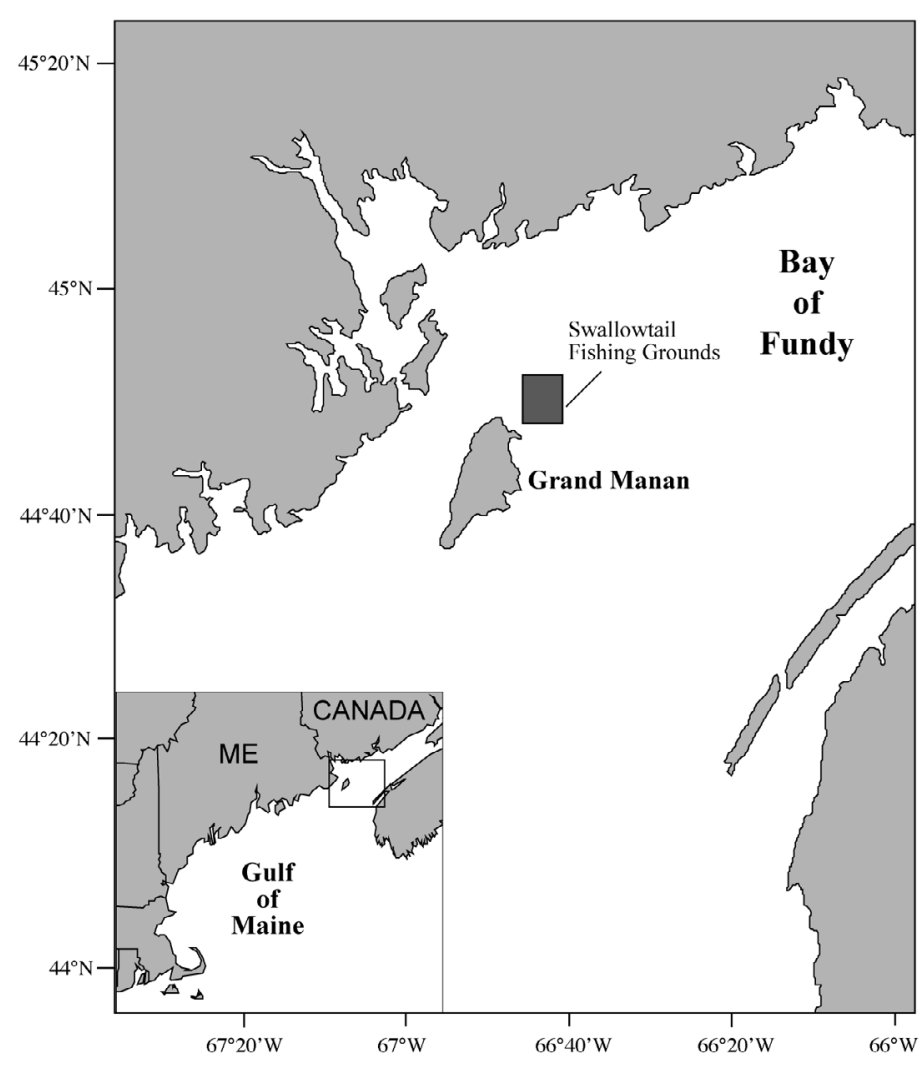

Fig. 1. Study area. Swallowtail Fishing Grounds (shaded box) NE of Grand Manan Island, New Brunswick, Canada

Each gill net string consisted of 3 nets, each $100 \mathrm{~m}$ long, tied together with bridles (Read \& Gaskin 1988). We attached 4 Porpoise Echolocation Detectors (PODs) to the float line, 1 on each end of the string and 1 on each bridle. The PODs continuously recorded the number of echolocation clicks at $10 \mathrm{~s}$ intervals (POD details available at: www.chelonia.demon.co.uk/POD home.html). Each POD recorded several channels of echolocation clicks of varying duration and frequency. The frequencies were fixed at 50,93, and $132 \mathrm{kHz}$. Porpoises produce distinctive, narrow band echolocation clicks from 110 to $150 \mathrm{kHz}$ (Møhl \& Andersen 1973, Kamminga \& Wiersma 1981), so we only analyzed clicks at $132 \mathrm{kHz}$. Single click durations for harbor porpoises are typically $100 \mu \mathrm{s}$ (Møhl \& Andersen 1973), so the PODs were programmed to capture any click that lasted up to $400 \mu \mathrm{s}$. The PODs were individually identified, and because of variation in their sensitivity, we always placed the same POD in the same position on the string (i.e. either on an end or on a bridle). We deployed PODs on both experimental nets and control nets. The PODs often recorded false clicks in the handling process, so we discarded the first and last $30 \mathrm{~min}$ of data for each set.
From the POD data, we identified 2 response variables: echolocation rate (the number of clicks recorded $\mathrm{h}^{-1}$ ) and echolocation occurrence (the proportion of $10 \mathrm{~s}$ intervals during which clicks were detected $\mathrm{h}^{-1}$ ). These response variables were chosen to capture differences between click trains and click bursts. Kastelein et al. (1995) showed that 2 porpoises had a click train duration of 9 to $35 \mathrm{~s}$, whereas click burst duration was less than $9 \mathrm{~s}$. Therefore, changes in click trains would be captured both in echolocation rate and occurrence, whereas variation in click bursts would only be reflected in echolocation rate. We assumed independence among hours, because porpoises likely did not remain in the area longer than $1 \mathrm{~h}$ (Cox et al. 2001).

Individual PODs varied in their sensitivity, so we restricted our statistical analysis of treatment differences (control and experimental nets) to comparisons of individual PODs. Using SPSS, we conducted univariate factorial analyses of variance to examine variation in echolocation rate and echolocation occurrence as a function of the type of net and time of day. For echolocation occurrence, we compared means of hourly proportions for these treatments. We defined 'day' to occur between 07:00 and 18:59 h and 'night' to occur between 19:00 and 06:59 h. We also conducted Kruskal-Wallis tests to determine whether there was a difference in number of target fish (groundfish), dogfish, and crustaceans caught $\mathrm{h}^{-1}$ while the nets were set between the control and experimental nets. These values were calculated by dividing the total catch by the number of hours fished, as it was not possible to determine the number of fish captured $\mathrm{h}^{-1}$ in real time because the nets were set for long periods.

To determine which environmental, spatial, or fishing-related variables were most closely correlated with echolocation behavior, we conducted simple and partial Mantel tests (Mantel 1967). Mantel tests are nonparametric tests of correlations among pair-wise dissimilarity matrices. The simple Mantel test allowed us to test for correlations between 2 variables (e.g. space and echolocation rate). A partial Mantel test is a multivariate linear regression that accounts for the spatial autocorrelation and intercorrelation of all the variables. For example, we tested for the relationship between echolocation rate and depth, given spatial autocorrelation and the intercorrelation of depth and echolocation rate with all other variables. We tested the correlation of 6 variables to echolocation rate and occurrence: spatial location, number of groundfish caught $\mathrm{h}^{-1}$, number of spiny dogfish Squalus acanthias caught $\mathrm{h}^{-1}$, number of crustaceans (lobsters and crabs) caught $\mathrm{h}^{-1}$, type of net, and depth of set.

The Mantel test evaluates the correlation between distance matrices, calculated using pair-wise distances. Thus, it tests whether points close in one value 
(e.g. space) are also close in another value (e.g. echolocation rate). We calculated spatial distance by Euclidean distance between points. For all other variables, the difference was the absolute difference. For type of net, we used 0 for the control net and 1 for the experimental net, thus creating a distance matrix containing 0 s (similar nets) and 1s (dissimilar nets).

The values in the distance matrices were not independent, so we conducted permutation procedures to determine significance. We permuted the rows and columns 1000 times and compared the observed Mantel's coefficients to the distribution of the generated coefficients to determine a significance level of 0.05 (Manly 1991). We conducted Mantel's tests in SPSS with the ecodist extension (Urban et al. 2002). Finally, to illustrate the outcome, we constructed path diagrams to represent hypothetical causal relationships, based on the partial Mantel's statistics. Path diagrams are not analyses in themselves, but allow interpretation of the data. (For a more detailed explanation of Mantel tests and path diagrams, see Schick \& Urban 2000.)

\section{RESULTS}

PODs were deployed on 14 control and 9 experimental nets. Soak times varied from 24 to $72 \mathrm{~h}$. In total, $467 \mathrm{~h}$ of control and $271 \mathrm{~h}$ of experimental data were obtained. We removed periods during which the nets were set and hauled. In addition, 1 POD malfunctioned, so we analyzed 366 h of data for control nets and 225 for experimental nets. No porpoises were caught in nets equipped with PODs during the course of our experiment.

Neither echolocation rate nor echolocation occurrence differed between the 2 types of net (Table 1). The power for our analysis from PODs 15, 16, and 19 (Table 1) was insufficient to accept the null hypothesis of no difference, but this was driven by 1 set in which we recorded virtually no echolocation. When we analyzed the difference in echolocation without this outlier, our power increased to a level at which we could accept our null hypothesis of no difference in echolocation rate and occurrence between the commercial and experimental nets (Table 1). Both echolocation rate and echolocation occurrence were greater during the day than at night for all 4 PODs (Table 2).

Results of the Mantel tests (Table 3, Fig. 2) showed a consistent correlation between echolocation and number of groundfish caught $\mathrm{h}^{-1}$ (6 of 8 tests), once spatial autocorrelation and intercorrelation were accounted for. Net type was never correlated with echolocation behavior. Depth was correlated with echolocation in 5 of the 8 Mantel tests. Additionally, depth was the only spatially autocorrelated variable, although echolocation occurrence and rate were spatially autocorrelated in 2 of the 8 tests (Mantel $r=0.16,0.13 ; \mathrm{p}=0.022,0.048$ ) and marginally non-significant (Mantel $r=0.16,0.11 ; \mathrm{p}=0.078$,

Table 1. Echolocation rate (number of clicks $\mathrm{h}^{-1}$ ) and echolocation occurrence (number of $10 \mathrm{~s}$ intervals positive for echolocation clicks $\mathrm{h}^{-1}$ ) in control and experimental nets. Means are reported with their associated standard errors. $1-\beta$ represents the power of the statistical test. A power of greater than 0.8 is considered sufficient to accept the null hypothesis of no difference in fish catch between net types (Peterman 1990). The power in parentheses is when the outlier on 16 August was removed

\begin{tabular}{|lcccc|}
\hline & POD 14 & POD 15 & POD 16 & POD 19 \\
\hline Echolocation rate & & & & \\
Control & $33.8 \pm 2.4$ & $169.4 \pm 9.6$ & $76.7 \pm 4.7$ & $170.3 \pm 10.4$ \\
Experimental & $32.4 \pm 2.7$ & $147.6 \pm 10.2$ & $68.2 \pm 5.0$ & $151.5 \pm 11.7$ \\
$F$-value & 0.28 & 2.95 & 1.55 & 1.59 \\
$\mathrm{df}$ & 1 & 1 & 1 & 1 \\
$\mathrm{p}$ & 0.60 & 0.09 & 0.21 & 0.21 \\
$1-\beta$ & $0.92(0.95)$ & $0.60(0.84)$ & $0.76(0.92)$ & $0.76(0.91)$ \\
Echolocation occurrence & & & & \\
Control & $17.0 \pm 0.9$ & $57.1 \pm 2.3$ & $32.8 \pm 1.6$ & $55.0 \pm 2.2$ \\
Experimental & $17.5 \pm 1.2$ & $53.6 \pm 3.0$ & $32.5 \pm 2.0$ & $52.4 \pm 3.1$ \\
$F$-value & 0.03 & 1.20 & 0.03 & 0.63 \\
$\mathrm{df}$ & 1 & 1 & 1 & 1 \\
$\mathrm{p}$ & 0.87 & 0.27 & 0.86 & 0.43 \\
$1-\beta$ & $0.83(0.95)$ & $0.81(0.95)$ & $0.95(0.89)$ & $0.88(0.95)$ \\
& & & & \\
\hline
\end{tabular}

Table 2. Echolocation rate (number of clicks $\mathrm{h}^{-1}$ ) and echolocation occurrence (number of $10 \mathrm{~s}$ intervals positive for echolocation clicks $\mathrm{h}^{-1}$ ) during the day and night. Means are reported with their associated standard errors

\begin{tabular}{|lcccc|}
\hline & POD 14 & POD 15 & POD 16 & POD 19 \\
\hline Echolocation rate & & & & \\
Day & $38.9 \pm 3.0$ & $193.0 \pm 12.1$ & $93.8 \pm 6.1$ & $196.0 \pm 13.5$ \\
Night & $28.5 \pm 2.2$ & $132.8 \pm 7.8$ & $55.9 \pm 6.1$ & $133.5 \pm 8.2$ \\
$F$-value & 5.22 & 12.89 & 25.15 & 12.81 \\
df & 1 & 1 & 1 & 1 \\
p & 0.023 & 0.00 & 0.00 & 0.00 \\
$1-\beta$ & 0.37 & 0.08 & 0.00 & 0.05 \\
Echolocation occurrence & & & & \\
Day & $20.2 \pm 1.2$ & $64.6 \pm 2.9$ & $40.5 \pm 2.0$ & $62.7 \pm 2.9$ \\
Night & $14.7 \pm 0.9$ & $48.0 \pm 2.2$ & $26.0 \pm 1.4$ & $46.3 \pm 2.2$ \\
$F$-value & 9.03 & 15.37 & 28.29 & 15.90 \\
df & 1 & 1 & 1 & 1 \\
p & 0.00 & 0.00 & 0.00 & 0.00 \\
$1-\beta$ & 0.15 & 0.02 & 0.00 & 0.02 \\
& & & & \\
\hline
\end{tabular}


0.095) in 2 others. The correlation between echolocation and number of groundfish caught was driven by 1 set, and, after we removed that point, the significant correlation between groundfish and echolocation occurrence and rate disappeared. However, the correlation between echolocation behavior and depth remained.

Catches of groundfish (cod, pollock, haddock and hake) and dogfish, corrected for soak time, did not differ with net type (Table 4). Significantly more crustaceans were caught in experimental than control nets (Table 4). The crustacean catch was comprised mostly (90\%) of American lobsters Homarus americanus; most lobsters were released alive.

\section{DISCUSSION}

Our observations do not support the hypothesis of change in echolocation behavior, and we conclude that porpoises did not respond to the acoustic reflectivity of the experimental nets. Neither the analysis of variance nor the Mantel test results indicated that porpoises responded to the acoustic reflectivity of the net by a change in click frequency or click train production.

Harbor porpoises may use click trains for navigation, whereas click bursts are used for investigation of objects (Verboom \& Kastelein 1995). If porpoises had responded to the acoustic reflectivity of the monofilament by further investigation of the net, we would have expected to see an increase in click bursts (i.e. echolocation rate but not occurrence). If porpoises had responded to the acoustic reflectivity of the monofilament by navigating around the nets and avoiding them, we would have expected to see an increase in number of click trains (i.e. both echolocation rate and occurrence). Neither response was observed. We therefore conclude that the mechanism by which the experimental nets reduced by-catch of harbor porpoises in previous studies is unrelated to the acoustic properties of the nets.

Table 3. Mantel $r$ coefficients and p-values (ns = non-significant) for results of simple and partial Mantel test for each individual POD for echolocation rate and occurrence. 'Rate' or 'Occurrence' represent the simple correlation of echolocation rate or occurrence to each individual variable. 'Space' represents the correlation of each variable to space. $\rho$ RX|S represents the Mantel $r$ coefficients for the correlation between echolocation rate or occurrence and the variable, once spatial autocorrelation has been taken into account, and $\rho \mathrm{RX|}{ }^{*}$ represents the correlation of each variable and echolocation rate or occurrence, given spatial autocorrelation and intercorrelation of variables

\begin{tabular}{|c|c|c|c|c|c|c|c|c|c|}
\hline Rate & Rate & Space & $\rho R X \mid S$ & $\left.\rho R X\right|^{*}$ & Occurrence & Occurrence & Space & $\rho \mathrm{RX} \mid \mathrm{S}$ & $\left.\rho \mathrm{RX}\right|^{*}$ \\
\hline POD 14 & & & & & POD 14 & & & & \\
\hline Rate & - & $0.21(0.002)$ & - & $0.16(0.022)$ & Occurrence & - & $0.18(0.007)$ & - & $0.11(0.078)$ \\
\hline Depth & $0.13(0.055)$ & $0.56(0.001)$ & ns & ns & Depth & $0.15(0.019)$ & $0.56(0.001)$ & ns & ns \\
\hline Groundfish & $-0.22(0.004)$ & ns & $-0.24(0.001)$ & $-0.27(0.002)$ & Groundfish & $-0.21(0.002)$ & ns & $-0.23(0.002)$ & $-0.26(0.001)$ \\
\hline Dogfish & $-0.19(0.013)$ & ns & $-0.18(0.018)$ & $-0.23(0.001)$ & Dogfish & $-0.14(0.036)$ & ns & $-0.13(0.061)$ & $-0.18(0.007)$ \\
\hline Crustaceans & ns & ns & ns & ns & Crustaceans & ns & ns & $-0.11(0.076)$ & $-0.13(0.42)$ \\
\hline Type & $\mathrm{ns}$ & $\mathrm{ns}$ & ns & ns & Type & ns & ns & $\mathrm{ns}$ & ns \\
\hline POD 15 & & & & & POD 15 & & & & \\
\hline Rate & - & $0.20(0.004)$ & - & $0.11(0.095)$ & Occurrence & - & $0.27(0.001)$ & - & ns \\
\hline Depth & $0.22(0.001)$ & $0.56(0.001)$ & $0.13(0.044)$ & $0.16(0.013)$ & Depth & $0.45(0.001)$ & $0.56(0.001)$ & $0.37(0.001)$ & $0.39(0.001)$ \\
\hline Groundfish & $-0.21(0.001)$ & ns & $-0.24(0.001)$ & $-0.25(0.001)$ & Groundfish & $-0.15(0.025)$ & $\mathrm{ns}$ & $-0.17(0.004)$ & $-0.22(0.001)$ \\
\hline Dogfish & ns & ns & ns & ns & Dogfish & ns & ns & $0.13(0.057)$ & ns \\
\hline Crustaceans & $-0.16(0.02)$ & $\mathrm{ns}$ & $-0.17(0.01)$ & $-0.16(0.01)$ & Crustaceans & $-0.13(0.037)$ & $\mathrm{ns}$ & $-0.15(0.028)$ & $-0.12(0.068)$ \\
\hline Type & ns & $\mathrm{ns}$ & ns & ns & Type & $\mathrm{ns}$ & ns & $\mathrm{ns}$ & ns \\
\hline POD 16 & & & & & POD 16 & & & & \\
\hline Rate & - & $0.19(0.004)$ & - & $0.13(0.048)$ & Occurrence & - & $0.21(0.002)$ & - & ns \\
\hline Depth & $0.16(0.019)$ & $0.56(0.001)$ & ns & ns & Depth & $0.25(0.001)$ & $0.56(0.001)$ & $0.17(0.016)$ & $0.18(0.004)$ \\
\hline Groundfish & $-0.16(0.024)$ & ns & $-0.18(0.01)$ & $-0.18(0.007)$ & Groundfish & $-0.18(0.007)$ & ns & $-0.20(0.001)$ & $-0.21(0.002)$ \\
\hline Dogfish & ns & $\mathrm{ns}$ & ns & ns & Dogfish & ns & ns & ns & ns \\
\hline Crustaceans & $-0.15(0.018)$ & $\mathrm{ns}$ & $-0.16(0.014)$ & $-0.15(0.019)$ & Crustaceans & $-0.12(0.054)$ & ns & $-0.13(0.045)$ & $-0.12(0.064)$ \\
\hline Type & ns & ns & ns & ns & Type & ns & ns & ns & ns \\
\hline POD 19 & & & & & POD 19 & & & & \\
\hline Rate & - & $0.34(0.001)$ & - & ns & Occurrence & - & $0.34(0.001)$ & - & ns \\
\hline Depth & $0.47(0.001)$ & $0.35(0.001)$ & $0.35(0.001)$ & $0.32(0.001)$ & Depth & $0.52(0.001)$ & $0.35(0.001)$ & $0.41(0.001)$ & $0.40(0.001)$ \\
\hline Groundfish & ns & ns & ns & ns & Groundfish & ns & ns & ns & $-0.15(0.059)$ \\
\hline Dogfish & $\mathrm{ns}$ & $\mathrm{ns}$ & ns & $\mathrm{ns}$ & Dogfish & ns & $\mathrm{ns}$ & $\mathrm{ns}$ & ns \\
\hline Crustaceans & ns & $-0.19(0.064)$ & $-0.19(0.016)$ & ns & Crustaceans & ns & $-0.19(0.064)$ & $-0.16(0.055)$ & ns \\
\hline Type & ns & ns & ns & ns & Tyре & ns & ns & ns & ns \\
\hline
\end{tabular}



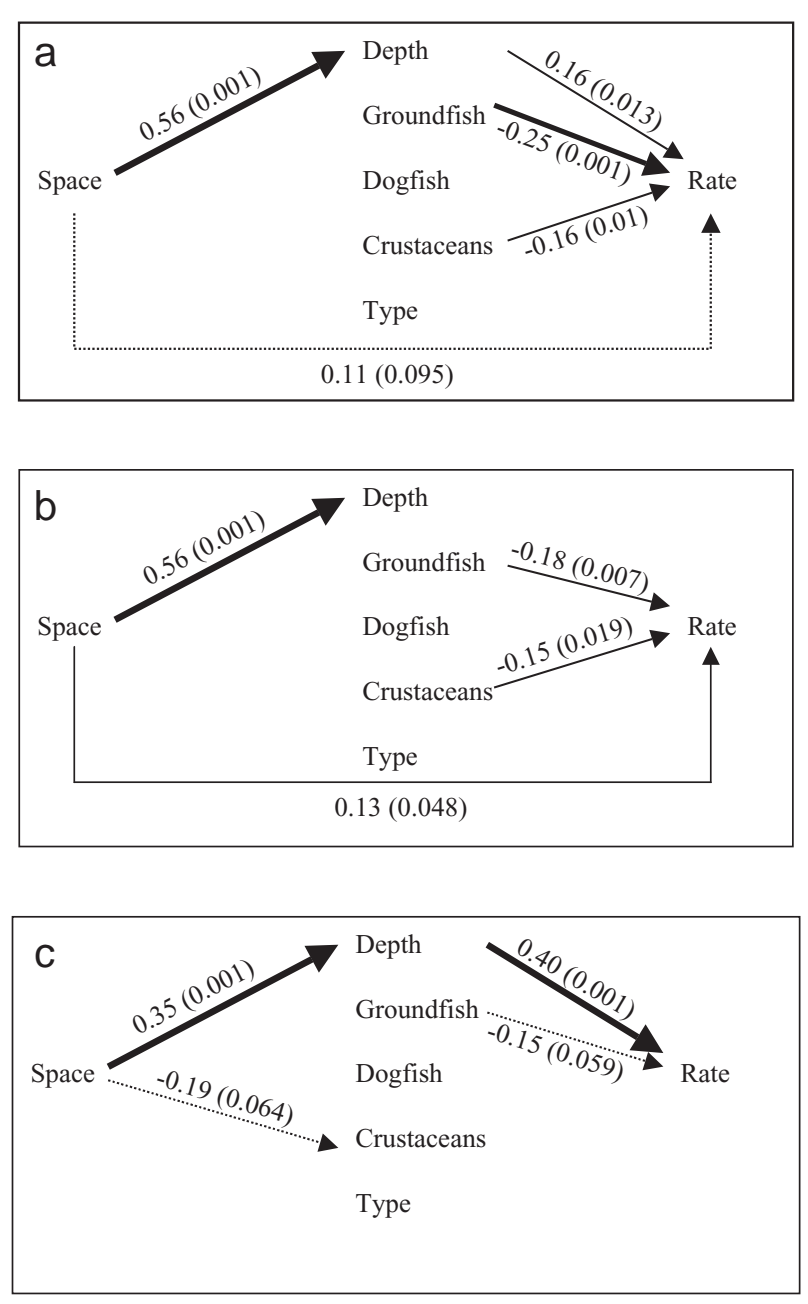

Fig. 2. Path diagrams representing results from Table 3. (a) Echolocation rate, POD 15; (b) echolocation rate, POD 16; (c) echolocation occurrence, POD 19. Dashed lines represent marginally non-significant relationships. Significant Mantel $r$ coefficients are shown with the respective p-value in parentheses. Thickness of the line coincides with $r$-value. Arrows represent hypothetical direction of causation

Table 4. Comparison of number of groundfish, dogfish, and crustaceans caught per hour the net was set, for control and experimental nets. Means are reported with their standard errors. $1-\beta$ represents the power of the statistical test. A power of greater than 0.8 is considered sufficient to accept the null hypothesis of no difference in fish catch (Peterman 1990)

\begin{tabular}{|lccc|}
\hline & Groundfish & Dogfish & Crustaceans \\
\hline Control & $0.38 \pm 0.05$ & $1.7 \pm 0.56$ & $0.0032 \pm 0.0009$ \\
Experimental & $0.41 \pm 0.10$ & $0.74 \pm 0.25$ & $0.1164 \pm 0.032$ \\
$\chi^{2}$ & 0.04 & 1.1 & 6.3 \\
$\mathrm{df}$ & 1 & 1 & 1 \\
$\mathrm{p}$ & 0.85 & 0.28 & 0.01 \\
$1-\beta$ & 0.94 & 0.76 & 0.07 \\
\hline
\end{tabular}

Understanding how these nets reduce by-catch is critical to predicting the long-term effectiveness of this mitigation measure and its potential to be effective in other regions and with other species. Larsen et al. (2002) posed several hypotheses as to why significantly fewer porpoises were caught in chemically enhanced nets in North Sea trials. They showed that the experimental nets did not have higher target strength than standard commercial gill nets, supporting our conclusion that porpoises do not respond to the acoustic nature of the nets. Rather, Larsen et al. (2002) suggested that the decreased by-catch observed in modified nets was due to (a) their increased stiffness, (b) their color, or (c) the different behavior of these nets in the water column. In particular, Larsen et al. reported that chemically enhanced nets were significantly stiffer, and hypothesized that this difference could lead fewer porpoises to become entangled. The nets used in the Danish trials were red. The nets in our study were blue, as opposed to the traditional green of commercial gill nets. However, in the Bay of Fundy, gill nets are set at depths of over $100 \mathrm{~m}$ where visual perception of the difference between blue and green monofilament by porpoises seems unlikely.

Fishermen on Grand Manan Island believe that their nets lie on the sea floor at certain tidal phases due to the extreme currents in the Bay of Fundy (M. Simms, FV 'Saratogian', pers. comm.). The nets will fish efficiently for groundfish only when they are oriented upright in the water column. The experimental nets we tested were filled with $\mathrm{BaSO}_{4}$, making them heavier than traditional gill nets used in the region. It is possible that the experimental nets, due to this increased weight, were lying on the seafloor longer than the control nets, reducing the amount of time porpoises are vulnerable to entanglement. This supposition is supported by the increased crustacean catch we observed in experimental nets, although we did not observe a significant difference in fish catches. A significant reduction in catches of cod was observed in the North Sea trials. Larsen et al. (2002) did not detect a significant difference in height of the 2 nets when placed in a flow tank with flow speeds up to 1 knot. However, it was noted that the height of the experimental nets tended to be more reduced by the flow than the control nets. Currents in the Bay of Fundy are 4 times this velocity, so it is possible that the heavier, experimental nets were fishing for significantly less time.

If these modified nets reduce by-catch because of their stiffness or increased weight, fishermen would have an effective and inexpensive alternative with which to reduce porpoise by-catch. Chemically enhanced nets are extremely expensive due to the costly procedure of filling monofilament twine with a metal. 
We suggest that the same by-catch reduction might be attained with a net that is simply stiffer or heavier and not chemically enhanced; field trials of such simple modifications are required.

Echolocation behavior of porpoises varied with depth, space, and time of day. These differences could be attributed to the number of porpoises around the nets or differences in their echolocation behavior. Unfortunately, we were unable to make synoptic estimates of porpoise abundance around the nets, so we can only speculate as to which explanation is most likely. Porpoises are capable of diving to depths over $200 \mathrm{~m}$, but few dives are made so deep (Westgate et al. 1995). This effect may be related to the vertical distribution of their prey. Atlantic herring Clupea harengus, the primary prey of harbor porpoises in the Bay of Fundy, can be found as deep as $500 \mathrm{~m}$, but they occur more frequently at 50 to $100 \mathrm{~m}$ (Blaxter \& Hunter 1982). The correlation between space and echolocation behavior may be due to the horizontal distribution of herring. Atlantic herring are a schooling fish, and therefore have a patchy distribution. Porpoises are likely to respond to prey distribution, and therefore also show a patchy distribution.

In the bottom-set gill nets, less echolocation was recorded at night. In a previous study, we documented less echolocation at the surface during the day (Cox et al. 2001). Atlantic herring are diel vertical migrators, spending time near the surface at night and migrating downward during the day (Blaxter \& Hunter 1982). Porpoises are likely following herring vertical migrations, spending more time at the surface at night and more time at depth during the day. These findings apparently contradict those of Westgate et al. (1995), which showed that porpoises make deeper dives at night. However, the findings of Westgate et al. (1995) were based on a very small sample $(n=7)$ of porpoises, which were monitored for short periods (mean = $36.3 \mathrm{~h}$ ) after capture and handling. Future studies of diving behavior and echolocation should resolve this apparent contradiction. It is important to note that porpoises may be less vulnerable to entanglement at night if they are not diving to the depths at which bottom-set nets are set.

\section{CONCLUSION}

The primary objective of this study was to elucidate possible mechanisms by which chemically enhanced nets reduce by-catch of harbor porpoises. Neither echolocation rate nor occurrence varied with the type of net, leading us to conclude that the mechanism by which the experimental nets reduced by-catch is not related to acoustic reflectivity; rather, these nets likely catch fewer porpoises because of their stiffness or increased weight. Field trials of stiff or heavy nets are required to determine whether such simple modifications can reduce the by-catch of small cetaceans in the world's fisheries.

Acknowledgements. This study would not have been possible without the cooperation of M. Simms and the crew of the FV 'Saratogian'. We would also like to thank E. Trippel and the Canadian Department of Fisheries and Oceans for allowing us to collaborate with their study. The research was conducted with the support of the Grand Manan Whale and Seabird Research Station and the Grand Manan Fishermen's Association. We purchased PODs with funds from World Wildlife Fund, Oak Foundation, and the Humane Society of the United States. The manuscript was greatly improved by comments from 3 anonymous reviewers.

\section{LITERATURE CITED}

Au WWL (1993) The sonar of dolphins. Springer-Verlag, New York

Au WWL (1994) Sonar detection of gill nets by dolphins: theoretical predictions. Rep Int Whal Comm (Spec Iss) 15: 565-571

Blaxter JHS, Hunter J (1982) The biology of clupeoid fishes. In: Blaxter JHS, Russell FS, Younger M (eds) Advances in marine biology, Vol 20. Academic Press, London, p 3-223

Cox TM, Read AJ, Solow A, Tregenza N (2001) Will harbour porpoises (Phocoena phocoena) habituate to pingers? J Cetacean Res Manage 3:81-86

Dawson SM (1994) The potential for reducing entanglement of dolphins and porpoises with acoustic modifications of gill nets. Rep Int Whal Comm (Spec Iss) 15:573-578

Hatakeyama Y, Soeda H (1990) Studies of echolocation of porpoises taken in salmon gillnet fisheries. In: Thomas JA, Kastelein RA (eds) Sensory abilities of cetaceans: laboratory and field experience. Plenum Press, New York, p 269-281

Hatakeyama Y, Ishii K, Akamatsu T, Soeda H, Shimamura T, Kojima R (1994) A review of studies on attempts to reduce the entanglement of the Dall's porpoise, Phocoenoides dalli, in the Japanese salmon gillnet fishery. Rep Int Whal Comm (Spec Iss) 15:549-563

International Whaling Commission (2001) Report of the scientific committee. Annex L. Report of the workshop on bycatch mitigation measures in static fisheries. J Cetacean Res Manage 3(Suppl):292-296

Jones G, Sayigh L (2002) Geographic variation in rates of vocal production of free-ranging bottlenose dolphins. Mar Mamm Sci 18:374-393

Kamminga C, Wiersma H (1981) Investigations of cetacean sonar II: acoustic similarities and differences in odontocete sonar signals. Aquat Mamm 8(2):41-62

Kastelein RA, de Haan D, Staal C (1995) Behaviour of harbour porpoises (Phocoena phocoena) in response to ropes. In: Nachtigall PE, Lien J, Au WL, Read AJ (eds) Harbour porpoises: laboratory studies to reduce bycatch. De Spil Publishers, Woerden, p 69-90

Kastelein RA, Au WWL, de Haan D (2000) Detection distances of bottom-set gill nets by harbour porpoises (Phocoena phocoena) and bottlenose dolphins (Tursiops truncatus). Mar Environ Res 49:359-375

Kraus SD, Read AJ, Solow A, Baldwin K, Spradlin T, Anderson E, Williamson J (1997) Acoustic alarms reduce porpoise mortality. Nature 388:525 
Larsen F, Eigaard OR, Tougaard J (2002) Reduction of harbour porpoise by-catch in the North Sea by high-density gill nets. IWC Scientific Committee Working Paper SC/54/SM30, International Whaling Commission, Cambridge

Manly BFJ (1991) Randomization and Monte Carlo methods in biology. Chapman \& Hall, London

Mantel N (1967) The detection of disease clustering and a generalized regression approach. Cancer Res 27:209-220

Møhl B, Andersen S (1973) Echolocation: high-frequency component in the click of the harbour porpoise (Phocoena phocoena L.). J Acoust Soc Am 54:1368-1372

Perrin WF, Donovan GP, Barlow J (eds) (1994) Gill nets and cetaceans. Rep Int Whal Comm, (Spec Iss 15)

Peterman RM (1990) Statistical power analysis can improve fisheries research and management. Can J Fish Aquat Sci 47:2-15

Read AJ, Gaskin DE (1988) Incidental catch of harbor porpoises by gill nets. J Wildl Manag 52:517-523.

Read AJ, Drinker P, Northridge S (2003) By-catches of marine mammals in US fisheries and a first attempt to estimate the magnitude of global marine mammal by-catch. Paper SC/55/BC5 presented to the scientific committee of the International Whaling Commission, Berlin. International Whaling Commission, Cambridge

Editorial responsibility: Otto Kinne (Editor), Oldendorf/Luhe
Reeves RR, Smith BD, Crespo E, Notarbartolo di Sciara G (2003) Dolphins, whales, and porpoises: 2003-2010 conservation action plan for the world's cetaceans. Species Survival Commission, IUCN, Gland

Schick RS, Urban DL (2000) Spatial components of bowhead whale (Balaena mysticetus) distribution in the Alaskan Beaufort Sea. Can J Fish Aquat Sci 57:2193-2200

Silber GK, Waples KA, Nelson PA (1994) Response of freeranging harbour porpoises to potential gillnet modifications. Rep Int Whal Comm (Spec Iss) 15:579-584

Trippel EA, Holy NL, Palka DL, Shepard TD, Melvin GD, Terhune JM (2003) Nylon barium sulfate gillnet reduces porpoise and seabird mortality. Mar Mamm Sci 19:240-243

Tyack PL (1999) Communication and cognition. In: Reynolds JE, Rommel SA (eds) Biology of marine mammals. Smithsonian Institution Press, Washington, DC, p 423-484

Urban D, Goslee S, Pierce K, Lookingbill T (2002) Extending community ecology to landscapes. Ecoscience 9:200-212

Verboom WC, Kastelein RA (1995) Acoustic signals of harbour porpoises (Phocoena phocoena). In: Nachtigall PE, Lien J, Au WL, Read AJ (eds) Harbour porpoises: laboratory studies to reduce bycatch. De Spil Publishers, Woerden, p 1-40

Westgate AJ, Read AJ, Berggren P, Koopman HN, Gaskin DE (1995) Diving behaviour of harbour porpoises, Phocoena phocoena. Can J Fish Aquat Sci 52:1064-1073

Submitted: September 5, 2003; Accepted: May 13, 2004 Proofs received from author(s): September 17, 2004 